Kairos. Journal of Philosophy \& Science 21, 2019 Center for the Philosophy of Sciences of Lisbon University

\title{
Da Percepção Estética da Natureza à Acção - Uma Pedagogia Ambiental
}

\author{
Maria José Varandas \\ Centro de Filosofia da Universidade de Lisboa \\ ambientesea@gmail.com
}

Resumo Afirmando que a problemática ambiental impõe um novo paradigma ético que realize a unidade das faculdades (sensibilidade, entendimento e razão prática) na unidade da acção, este artigo defende uma pedagogia centrada no estímulo da sensibilidade ao belo natural em articulação com o sentimento moral, como via privilegiada de enfrentamento da crise ecológica contemporânea. Na transição para uma dimensão inclusiva e planetária do conceito de cidadania, em tanto que expressão de um agir responsável e comprometido no colectivo em que é, a educação ambiental impõe-se como protagonista fundamental na formação de cidadãos capazes de pensar e agir ambientalmente.

Palavras-chave Educação ambiental, estética natural, ética ambiental, biofilia, ambiente.

Abstract Claiming that we need a new paradigm which realizes the unity of human's faculties - sensibility, cognition and practical reason - on the ground of action, this paper argues that environmental education is the way to face ecological crisis, by stimulating the sensibility toward natural beauty and expanding the moral feelings that arise from it. We stand, therefore, that sensitivity and respect for nature or natural realities is the structural condition for a global citizenship and a globally committed action that must be promoted by a clearly integrated environmental education in public educational programs.

Key-Words Environmental education, natural aesthetics, environmental ethics, biophilia, environment.

DOI 10.2478/kjps-2019-0005

1. Desde os anos sessenta do século XX, a filosofia da natureza (em qualquer das suas modalidades), tem vindo a afirmar que o grau de ameaça da crise ecológica contemporânea implica o repensar da relação

O Open Access. (C) 2019 M.J. Varandas, published by Sciendo. (cc) BY-NC-ND This work is licensed under the Creative Commons Attribution-NonCommercial-NoDerivatives 4.0 License. 
do ser humano com o mundo natural, tendo em vista a configuração de um novo paradigma ético capaz de realizar a unidade do ser humano na unidade da acção'. Tal significa que a sensibilidade, o entendimento e o raciocínio moral confluem numa consciência ecológica dirigida para a acção inclusiva, assumindo o significado de cidadania no sentido que lhe foi atribuído por Aldo Leopold - o ser humano como membro e cidadão pleno da comunidade biótica.

Já Kant e Schiller defendiam que a modelação de uma «bela alma», sensível e atenta à beleza do mundo, concorreria para o desenvolvimento de uma «boa alma», sugerindo a íntima e proficiente aliança entre a ética e a estética na formação do humano.Na mesma linha, afirmamos que o ponto de partida para um agir ético plenamente comprometido com o mundo, será uma pedagogia da sensibilidade que persuada, desde a infância, a prestar atenção às manifestações naturais de beleza que despertam admiração e suscitam o respeito. Com efeito, sendo o modo mais imediato e intuitivo de relação com a realidade, a sensibilidade estética será também a via em que mais precocemente se apreende o belo compreendendo- $o^{2}$, nessa apreensão, como «símbolo da moralidade». Será necessário por isso, a nosso ver, configurar uma pedagogia ambiental que pressuponha a correlação estrutural da faculdade estética com as outras faculdades, a partir de uma antropologia que afirma o humano como unidade bio-psico-sociológica dinâmica e aberta ao mundo (sociedade e ambiente natural), e que assume «A tese de que a identidade humana não é estático-contemplativa, mas dinâmico-histórica» ${ }^{3}$. Tal significa que tanto o entendimento, como a sensibilidade estética e a racionalidade prática são entendidos no seu significado filogenético, co-evoluindo e re-actualizando-se numa constante dialéctica com o meio, segundo variáveis conformes ao tipo, multiplicidade e amplitude de estímulos significativos. Daí considerarmos que o desenvolvimento das

\footnotetext{
1 Cohen in Soromenho-Marques, 1998, 128.

2 Usamos aqui o termo compreensão no sentido que lhe é dado por Krishnamurti, 1992, 29: «Com a palavra compreender não me refiro a algo intelectual... Só podemos compreender alguma coisa quando aplicamos a mente, o corpo, os sentidos, os olhos, os ouvidos, o nosso ser inteiro. E dessa compreensão nasce a acção total, e não uma acção fragmentária, contraditória».
}

3 Soromenho-Marques, 1998, 128. 
faculdades sociocognitivas exigirá apropriada estimulação a partir dos primeiros anos, capaz de cultivar a afinidade entre a espontaneidade da percepção estética da natureza e os sentimentos morais que daí emergem (respeito, cuidado, responsabilidade).

2. Rachel Carson é um nome de referência na literatura ambiental, autora da primeira obra que associa explicitamente a crise ecológica à acção irresponsável (Silent Spring, 1962). O rigor científico da sua análise aos impactes negativos na dinâmica dos ecossistemas provocados pela utilização massiva de pesticidas químicos constitui a expressão racional de uma funda sensibilidade à natureza e o lúcido sintoma da preocupação, sempre presente, com a acção ambientalmente insensível e irresponsável. Em 1956, o seu artigo para uma revista ("Help Your Child to Wonder") e publicado como livro, postumamente, em 1965 com o título The Sense of Wonder reflectia, de uma forma muito pessoal e lírica, esta preocupação, defendendo a importância do contacto directo com a natureza desde a infância, como a via estrutural para a formação de uma sensibilidade atenta à beleza e ao bem do mundo natural, enfim, como solo exemplar de germinação de uma humanidade plena, na sua acepção ética em que ser e agir concordam e constituem expressões manifestas do Sumo Bem Comunitário. Sublinhamos que Carson configura, através da sua obra e vida, uma forma de ser e de estar que assumida e exemplarmente conjuga a sensibilidade, o conhecimento e a acção, numa coerência cuja razão e sentido mergulha no enraizamento bio-ecológico, enquanto matriz estrutural e primordial do ser humano. Partindo do princípio que há na criança uma tendência inata de maravilhamento pela natureza e os seus detalhes, o livro The Sense of Wonder, procura ser um guia pedagógico para o adulto, dando pistas e ajudando-o a fazer florescer e a desenvolver todo esse potencial biofílico que está na base da curiosidade e sentido de descoberta infantis. Aliás, sublinhe-se, que a inteira obra de Rachel Carson, exprime, de diversos modos, um género de pensar que afirma a unidade entre a emoção e a racionalidade, e onde a sensibilidade estética surge como locus privilegiado para o florescimento do conhecimento comprovado e da acção responsável:

O mundo da criança é cheio de frescura, de novidade, de beleza, povoado de maravilhas e entusiasmo... Para a 
criança é menos importante saber do que sentir... Se os factos são as sementes que produzem mais tarde conhecimento e sabedoria, as emoções são o solo fértil no qual as sementes terão de crescer. Os anos da primeira infância são aqueles em que se prepara o solo. Uma vez despertadas as emoções - o sentido do belo, o entusiasmo pelo novo e desconhecido, o sentimento de simpatia, piedade, admiração e amor - surge então o desejo de conhecimento acerca do objecto da nossa reação emocional [...] Que valor tem preservar e reforçar esse sentido de respeito e admiração, esse reconhecimento de algo para além dos limites da existência humana? Será a exploração do mundo natural apenas uma maneira agradável de passar as horas douradas da infância ou será algo de mais profundo? Estou certa de que há algo de mais profundo, algo de duradouro e significativo [...] Aqueles que contemplam as belezas da terra encontram reservas de força que resistirão enquanto durar a vida. Existe beleza tanto simbólica como real na migração das aves, no fluxo e refluxo das marés, no botão fechado pronto para a eclosão da primavera. Há nos refrãos repetidos da natureza algo de infinitamente curativo ${ }^{4}$.

$4 \quad$ «A child world is fresh and new and beautiful, full of wonder and excitement... For the child is not half so important to know as to feel. If the facts are the seeds that later produce knowledge and wisdom, then the emotions and the impressions of the senses are the fertile soil in which the seeds must grow. The years of early childhood are the time to prepare the soil. Once the emotions have been aroused - a sense of the beautiful, the excitement of the new and the unknown, a feeling of sympathy, pity, admiration or love - then we wish for knowledge about the object of our emotional response [...] What is the value of preserving this sense of awe and wonder? Is the exploration of the natural world just a pleasant way to pass the golden hours of childhood or is there something deeper? [...] Those who contemplate the beauty of the earth find reserves of strength that will endure as long as life lasts. There is symbolic as actual beauty in the migration of the birds, the ebb and flow of the tides, the folded bud ready for the spring. There is something infinitely healing in the repeated refrains of nature» (Carson in Kellert, 2005, 72-73. Versão portuguesa, 2012, 41-67). De modo idêntico Emerson afirmava, «Para dizer a verdade poucos adultos conseguem ver a Natureza. A maior parte das pessoas não vêem o Sol. Pelo menos, têm um ver muito superficial. O Sol ilumina apenas os olhos do homem, mas brilha nos olhos e no coração de uma criança. O que ama a Natureza é aquele cujos sentidos exteriores e interiores estão ainda ajustados uns aos outros, o que guardou o espírito da infância mesmo na idade adulta» (Emerson, 2001, 19). 
Explicitamos que as «reservas de força» colhidas nesse sentido profundo que a exploração do mundo natural encerra, radicam, segundo Carson, na estrutural afinidade entre o humano e o mundo natural, nessa sua genuína e irremovível natureza própria enquanto ser da natureza esta "reserva de força" tem, a nosso ver e segunda a autora secundada por autores contemporâneos que adoptam a abordagem evolucionária na formação e desenvolvimento do senso moral, uma orientação clara para o respeito, o cuidado, a responsabilidade. Chamamos aqui a atenção para a Ética da terra de Aldo Leopold (1949), cujo postulado fundamental afirma a íntima conexão entre humanos e ambiente natural determinante da agência moral, mais especificamente, da responsabilidade que é inerente ao ser humano no contexto alargado da acção. Uma responsabilidade tanto mais premente, quanto se constata que o efeito perverso do império da tecnologia tem reduzido a faculdade estético-contemplativa a uma dimensão crepuscular, implicando, no seu imparável progredir, uma desvalorização do modo de ser estrutural do ser humano, a afinidade, ou seja, o ser-com-os-outros - humanos e não humanos.

O tema da afinidade natural entre o ser humano e o seu envolvente natural que Rachel Carson, Henry David Thoreau, Ralph Emerson, John Muir, Aldo Leopold, entre outros, intuíram, é colocado como hipótese de investigação por Edward Osborne Wilson na sua obra Biophilia (1984), tema que continua em The Biophilia Hypothesis (1993), em colaboração com Stephen Kellert. Especificamente, a questão da continuidade natureza-cultura e a tese de que há precursão genética na determinação das faculdades estética e ética é sustentada por uma consistente linha de investigação que evolui até a actualidade a partir das teses de Darwin (ver Kirchof, 20085). Na esteira do evolucionismo cultural, a hipótese da biofilia de Wilson estabelece a vinculação inata entre o ser humano e as outras formas de vida não-humanas, fruto da co-evolução genes/ cultura, e que, segundo o autor, necessita de um input constante a partir do meio natural, um conjunto rico e diversificado de experiências exploratórias em ambiente natural, que o cérebro humano vem prepa-

$5 \quad$ Kirchof sustenta a tese da continuidade natureza-cultura no livro Estética e Biossemiótica, 2008, através de uma sólida argumentação que demonstra a passagem gradual dos fenómenos estéticos da natureza (biosfera) para os fenómenos estéticos da cultura (semiosfera). 
rado para processar tendo em vista o seu amplo e completo desenvolvimento. Analogamente, Stephen Kellert (da área de Ecologia Social) afirma a necessidade de actualização das tendências inatas biofílicas mediante a aprendizagem em contexto natural que contemple a multi-dimensionalidade das funções humanas, seja a necessidade de conhecimento, seja o apelo estético, ou o reforço da afectividade ou ainda a expansão da criatividade e da imaginação. Analisando três formas de contacto com a natureza (directo - envolvimento físico em áreas naturais; indirecto participação em naturezas planeadas como zoos, jardins botânicos, museus de História Natural; simbólico - representações audiovisuais da natureza), Kellert (2002) considera que apenas a natureza vivida directamente concorre para o pleno desenvolvimento psicossomático e para a formação de uma consciência ambiental. Segundo o autor, tanto o contacto com a natureza em zoos como, sobretudo, a visão passiva de realidades naturais em écrans de televisão carecem de estímulos que desafiem activa e amplamente as capacidades criativas espontâneas que favorecem o comportamento adaptativo. No livro Birthright: People and Nature in the Modern World (2012) Kellert analisa a resposta estética ${ }^{6}$ à natureza considerando que esta decorre fundamentalmente de um acto de curiosidade provocado por um objecto natural que gera uma reacção (estética) que induz a observação e, frequentemente, a reflexão e a acção. Já Konrad Lorenz apontava o comportamento de curiosidade (Neugierverhalten) como o motor genético para a acção exploratória que gera o conhecimento do mundo externo, a pesquisa científica e a criação da obra de $a_{r t e}$. Lorenz integra as ideias de Darwin sobre a função da

$6 \quad$ Kellert (2012) identifica e explicita os traços psico-genéticos da relação humana com a natureza: atracção, aversão, razão, exploração, espiritualidade, ética (entre outros), demonstrando a fulcralidade dessa relação na formação e desenvolvimento do ser e considerando que o viver moderno constitui uma ilusão que antagoniza a cultura à natureza, colocando em risco o bem-estar humano e falseando o sentido profundo da humanidade. A partir da defesa da hipótese da biofilia e das teses leopoldianas, Kellert desenvolve um robusto trabalho de investigação dirigido à educação das crianças e à demonstração dos efeitos positivos da aprendizagem em espaços naturais livres.

7 «Quando a curiosidade encontra a sua ação final em algum estímulo externo, gera o comportamento explorativo que permite o conhecimento do mundo externo. Quando ele não se dirige por qualquer acção final específica gera uma Leerlaufhandlung: nesse caso, tem-se o comportamento lúdico ou jogo (Spiel)» (Kirchof, 2008, 47). Segundo Lorenz, o Spiel é mobilizado pelo prazer heurístico, é espontâneo e criativo, e pode orientar-se em 
aparência na defesa contra predadores e da beleza na selecção sexual, ampliando-Ihes o significado e convertendo-as numa espécie de código perceptivo do mundo externo que distingue o belo/saudável/atractivo, do feio/doente/repulsivo ${ }^{8}$. Coerente com esta linha teórica (etologia, biologia, sociobiologia), Kellert integra a resposta estética no contexto bio-psico-social evolucionário, admitindo que a reacção estética é uma forma de resolução adaptativa, ou seja, uma resposta especializada aos desafios particulares da sobrevivência através da qual o ser humano organiza a sua experiência e o seu mundo, integrando o particular em totalidades com sentido, ordenando, descobrindo simetrias, enfim, cosmicizando o caos e contribuindo para os sentimentos de segurança e conforto. Neste sentido, as vantagens adaptativas da atracção estética transformam-na numa via de coesão e sobrevivência da espécie que, por isso, se impregna biologicamente nos genes e se manifesta espontanea e sensivelmente.

Embora não possuindo a envergadura científica de Edward O. Wilson, ou o fôlego de investigação de Kellert (que tem produzido uma obra sólida e consistente, declaradamente tributária da Land Ethic e em defesa da hipótese da biofilia), também o mentor da Ética da terra, Aldo Leopold (1949) ${ }^{9}$, intuía a associação entre a beleza natural e a evolução adaptativa humana, sugerindo que a afinidade estética entre humanos e não humanos é um aspecto central da adaptação bio-ecológica e uma consequência da inter-relação natureza e homem. Biofilia, simbiose e simbiose benevolente ${ }^{10}$ são, nesta perspectiva, conceitos operativos epistemologicamente relacionados que admitem e expõem a natural afinidade do ser humano com a natureza, constituindo esta a matriz de onde brota a ética, a estética e todo o conjunto de representações culturais.

dois sentidos: por um propósito determinado e claro (pesquisa científica) ou permanece na esfera lúdica, livre e prazerosa (obra de arte).

8 Kirchof, 2008, 43.

9 «Leopold, reflecting on the perception of nature's beauty to an intuitive understanding of the health and integrity of natural systems, remarked: "A thing is right when it tends to preserve the integrity, stability, and beauty of the biotic community. It is wrong when it tends otherwise"» (Kellert, 2012, 3).

10 Varandas, 2003. 
Indo mais longe, as coordenadas gerais da hipótese da biofilia tendências inatas de conexão com a natureza, entre as quais se destaca a atracção estética - ao identificarem tendências formulam em simultâneo a necessidade que lhes é inerente - a sua estimulação em contexto ecológico, tendo em vista a actualização e o pleno desabrolhar da matriz biofílica. Daí que Kellert (2002) em linha com psicólogos, sociólogos e ecólogos sociais enfatize a fulcralidade do contacto com a natureza na infância (outdoor education) dirigido ao desenvolvimento harmonioso do potencial psico-cognitivo do $\operatorname{ser}^{11}$. O modelo teórico que informa as investigações multidisciplinares de Kellert segue Piaget e Köhlberg numa linha estruturalista-desenvolvimentista que integra o inato e o adquirido numa dinâmica de aprendizagem na qual o sujeito activamente constrói as estruturas cognoscitivas fundamentais à sua adaptação ao meio. Um modelo que, de igual modo, informa o trabalho do seu colega de investigação, o psicólogo Peter Kahn Jr., e que orientou o robusto estudo comparativo cross-cultural (um dos estudos foi realizado em Lisboa) que este investigador realizou sobre as percepções e representações gerais de crianças e adolescentes acerca da natureza/aspectos da natureza/ degradação ambiental (Kahn, 2002) e cujas conclusões demonstram que os sujeitos considerados encaram a natureza como uma fonte de múltiplos e variados estímulos que lhes permitem a construção estruturada de valores e de concepções sobre o mundo. A este respeito, Kellert (2005) cita a psicóloga Edith Cobb que, no seu estudo The Ecology of Imagination in Chidhood, constata que a maioria das pessoas mais dotadas atribuem à memória das suas vivências infantis em ambientes naturais a base emocional da sua produção criativa, forjando nelas o sentido do maravilhoso, o desejo de exploração e o impulso para a descoberta.

A situação actual se, por um lado, mostra uma diminuição do contacto directo com a natureza de uma geração para outra (um estudo dirigido às mães revela que $70 \%$ delas brincaram ao ar livre na infância, contra os $31 \%$ das suas crianças que actualmente o fazem ${ }^{12}$ ), por outro, indica

11 «Even in today"s world of accumulated knowledge and powerful electronic communication, the natural world remains the most sensory-stimulating and information-rich environment people ever encounter» (Kellert, 2012, 4).

12 «Not only have children's play environments dramatically changed in the last few decades, but also the time children have to play has decreased. Between 1981 and 1997, 
uma progressiva habituação a ambientes ecologicamente degradados (rios poluídos, lixo, desaparecimento de áreas arborizadas na vizinhança) que Kahn designa por «amnésia geracional ambiental» ${ }^{13}$. Com efeito, a sociedade urbana, hoje em dia, opta cada vez mais por formas de contacto simbólico com o ambiente natural, mediante o qual a criança configura representações formais e supervisionadas de uma natureza meramente virtual, num processo de "extinção» da experiência ${ }^{14}$ que parece correr em paralelo com a extinção global da biodiversidade. E, embora, um leque amplo de literatura especializada, escorada em investigações que contemplam inúmeros casos-de-estudo, aponte com reincidência os benefícios das afiliações positivas com a natureza no bem-estar cognitivo, psicológico, emocional e espiritual dos seres humanos, o progressivo empobrecimento e destruição do ambiente continua e concorre perigosamente para a destruição da maturação bem sucedida das aquisições e construções psicológicas da criança. Para Kahn a resolução de toda a problemática implicada na questão da «amnésia geracional ambiental», dado que esta tem a sua origem na infância, começa, justamente, pela própria infância:

Precisamos de comprometer as crianças numa educação ambiental construtivista a fim de maximizar a exploração e a interacção com a natureza que ainda existe ao seu alcance - insectos, animais domésticos, plantas, árvores, vento, chuva, solo, sol (...) Precisamos também de reconhecer que as crianças constroem o conhecimento e os valores não apenas através da interacção com o mundo físico, mas

the amount of time children ages 6 to 8 in the U.S. played decreased $25 \% \ldots$ a recent study surveyed mothers and found that $70 \%$ of mothers played outdoors everyday when they were children, compared only $31 \%$ of their children» (Kellert, 2005, 81).

13 «People take the natural environment they encounter during childhood as the norm against which they measure environmental degradation later in their life. With each ensuing generation, the amount of environmental degradation increases, but each generation takes that degraded conditions as the non-degraded condition, the normal experience... As we lose daily intimate positive affiliations with nature and accept negative experiences (such as pollution) as the norm, we suffer physically and psychologically and hardly know it» (Kahn, 2002, 113).

14 Kellert, 2002, 141. 
também através da interacção com o mundo social e com o discurso social ${ }^{15}$.

Por seu turno, Kellert sublinha que ainda não se conhecem, na sua total amplitude e a longo-prazo, os efeitos na maturação psico-cognitiva infantil de quotidianos pobres em estímulos apropriados e com escassas oportunidades de experiência directa no mundo natural. Pergunta Kellert, poderá o reforço substancial dos contactos indirectos ou simbólicos com a natureza substituir e, até, compensar a perda acelerada dos arrabaldes naturais próximos das habitações? O extraordinário aumento da informação tecnológica que proporciona o acesso a realidades naturais distantes e exóticas, ou o constante aperfeiçoamento no design de zoos e similares tendo em vista recriacções 'fidedignas' dos habitats originais constituirão uma vantagem geracional efectiva? Até agora, as investigações que procuram dar resposta a estas questões têm mostrado que os efeitos positivos no conhecimento pessoal das realidades naturais experienciadas de forma indirecta são transitórios e raramente contribuem de forma significativa para o desenvolvimento emocional e cognitivo da criança, talvez porque, como afirma Robert Pyle, as crianças necessitam de espaços livres para jogar às escondidas, subir uma árvore, trepar as rochas, descobrir atalhos por entre o matagal ${ }^{16}$, pois, como declara Rosario Assunto (Il Paesaggio e l'Estetica, 1973), é na infância que as coisas do mundo natural são intensamente vividas e é nesse solo vivencial que se dá a irrupção estética e se apreende o sentido originário do agir:

Aquela perene redescoberta da infância que é saborear uma amora, um mirtilo, um morango do bosque - ou, simplesmente, sentir o gosto salgado e iodado do ar marinho; ou então, como em certas longas tardes de Primavera, ter na boca, sem nada ter comido, um sabor tenro de clorofila,

15 «We need to engage children in a constructivist environmental education to maximize their exploitation of and interaction with nature that still exists within their purview - bugs, pets, plants, trees, wind, rain, spoil, sunshine (...) We also need to recognize that children construct knowledge and values not only through interaction with a physical world but through interaction with a social world and a social discourse» (Kahn, 2002, 113).

16 Kellert, 2005, 87. 
chegado com o vento. Sabores, cheiros; e a doçura da terra batida; a pedregosidade dos caminhos de montanha (...) este bem é sentido na experiência estética da paisagem como uma componente da sua beleza ${ }^{17}$.

Apesar da força e alcance universais das palavras de Assunto, a vivência infantil está, hoje, atolada de mecanismos tecnológicos e imersa na artificialidade que, pela sua própria dinâmica de falsificação, é fonte de alienação e de empobrecimento da pessoa e do cidadão futuros.

«Falta hoje um sentido generalizado de intimidade com o mundo vivo» ${ }^{18}$; uma intimidade que se funda na sensibilidade originária, participativa e comprometida com o mundo natural, desencadeada pela experiência viva e plena de «alegria» que, como afirmava Schiller, todos sorvemos do seio da natureza ${ }^{19}$. O contacto directo com os seres vivos (amoras, mirtilos, morangos, insectos, aves e mamíferos) e físicos (ar, solos, águas, rochas), afecta a criança de um modo que nenhuma experiência simbólica pode substituir. Porque a riqueza dessa relação estrutural modela e amplifica toda a riqueza multi-dimensional humana: o sentir em toda a sua gama de cambiantes (espanto, aversão, atracção, medo, afecto), o pensar (curioso, experimentalista ou meditativo), o comunicar, o criar, enfim, o pleno e harmonioso desenvolvimento das faculdades humanas que concorre para a modelação de uma «vontade boa» capaz de se interessar pela protecção das realidades não-humanas.

3. Neste ponto, é fundamental perceber como é que a partir da relação entre a sensibilidade inata do ser humano ao mundo natural e a emergência de sentimentos morais se passa para uma cidadania activa e ambientalmente responsável. Ao falarmos de cidadania entramos de imediato na esfera política. E é aqui justamente que se poderá atingir a compreensão pública do significado pleno e inclusivo do conceito, integrando comportamentos e actos no alargado horizonte socio-ecológico, pela reconfiguração da dimensão ético-jurídico-política do cidadão. Tarefa que assenta

17 Assunto, $2011,367-368$.

18 Pyle in Kellert, 2005, 84.

19 Assunto, $2011,372$. 
num programa de políticas públicas que, entre outros, contempla a formação da cidadania sócio-ambiental.

Em primeiro lugar, importa proceder a uma meditação breve sobre o significado de 'ambiente' que, dado o exposto, não pode ser reduzido ao de uma natureza 'exterior' ao homem, mas, pelo contrário, antes designa a natureza em co-determinação com o humano, ou seja, a natureza que é continuadamente afectada pela sua acção e, em reciprocidade, o afecta. Parafraseando Viriato Soromenho-Marques, a crise ecológica contemporânea mostra que ambiente significa hoje a natureza-posta-emperigo convocando, por isso, uma reflexão sobre os fundamentos do agir operadora de uma efectiva transformação conducente a um novo paradigma $^{20}$. Tão mais necessária quanto é por demais evidente que o perigo que ameaça o ambiente ameaça, em simultâneo, os seres humanos. A pertinente questão lançada por Soromenho-Marques «estaremos suficientemente maduros para aceitar os desafios desse novo paradigma emergente?» convoca reflexões de vária ordem. Seguramente de ordem ética, mas complementarmente clama pela clarificação do significado e estatuto ontológicos e axiológicos do humano e das realidades naturais. Será oportuno, por isso, o aprofundamento do sentido comum de ambiente, desprovido de consistência ontológica, entendido no modo instrumental de 'meio' como o conjunto de factores bio-físico-químicos que 'rodeiam' o mundo humano. Esta noção redutora que transforma o homem numa ilha, até pode ser acessível em manuais escolares 'primários' ou 'básicos' produzidos no interior de programas educativos neutros, fragmentados e sem uma orientação metodológica clara; mas não representa a complexidade do real e a complexidade das relações entre o ser/agente humanos e o seu horizonte natural. O conceito de ambiente é definido pela Lei de Bases do Ambiente (Lei n. ${ }^{\circ} 11 / 87$ ) «como o conjunto dos sistemas físicos, químicos, biológicos e suas relações, e dos factores económicos, sociais e culturais com efeito directo ou indi-

20 Soromenho-Marques (1998) identifica e analisa as dimensões inerentes à crise do ambiente cuja especificidade obriga a cultura a repensar-se à luz de um novo paradigma inclusivo do humano e da sua acção no horizonte natural. São elas: a dimensão planetária; a dimensão de irreversibilidade; a dimensão de aceleração cumulativa; a dimensão de descontrolo crescente; a distância entre a complexidade do real e o carácter redutor da sua representação. 
recto, mediato ou imediato, sobre os seres vivos e a qualidade de vida do homem»; na versão mais recente da Lei (19/2014) todo o articulado subentende como princípio e finalidade da política ambiental a «utilização racional dos recursos naturais». Ora, na perspectiva que defendemos, o ambiente é muito mais do que um factor de qualidade de vida ou do que o conjunto de aspectos físico-biológicos que circunda o ser humano, ou ainda do que uma arena de recursos que, racionalmente, deve ser preservada em prol das gerações futuras. Radicalmente, o ambiente é a natureza em co-determinação com o humano e por isso será o que, até certo ponto, determina o seu ser e o seu estar no mundo.

Compreender o ambiente não apenas como meio, mas como possuindo valor intrínseco comporta uma necessária reformulação dos direitos e deveres do agente humano, ampliando e aprofundando o significado de cidadania a uma dimensão planetária (Leopold) e a um horizonte temporal inclusivo do futuro (Jonas). Este paradigma ético que inclui «de forma explícita ou silenciada, uma antropologia, uma filosofia do direito e da política, uma concepção de episteme, uma concepção das relações de Cultura e Natureza» ${ }^{21}$ requer uma pedagogia que compreenda a educação ambiental, não como mero acessório educativo ou uma didáctica carregada de preceitos e normas, mas como a via de formação integral do ser humano a partir de uma representação do real integradora da actualidade histórica - indissociável da constatação do grau inédito de extensão do poder tecnológico com as suas implicações e desafios - em vista a um projecto de futuro desejável ${ }^{22}$.

No entanto, o olhar circunstancial sobre o panorama actual da Educação Ambiental [EA] revela sobretudo a fragmentação de princípios e estratégias, um pouco por todo o lado. A maior parte das vezes os seus programas são sobre o ambiente e contemplam apenas a informação das ciências naturais, numa orientação que tem em vista a formação de 'boas práticas' sustentáveis, ignorando inclusivamente, mesmo no seu objectivo de literacia, o potencial pedagógico que representa a informação não

21 Soromenho- Marques, 1998, 128.

22 «C'est là [essence de l'homme] que nous pouvons apprendre ce qui vaut la peine chez l'homme: que lui-même vaut donc la peine et que notre essence est digne d'avenir à savoir, digne de la chance toujours renouvelée que représente la possibilité du Bien.» (Jonas, 1998, 89-90). 
científica (conhecimento tradicional, mitos, lendas). Saliente-se ainda, como aponta Kellert (2005), que grande parte dos programas de educação ambiental para a infância são concebidos mais segundo a perspectiva do adulto do que da criança, não desenvolvendo nela a ligação e a sensibilidade à natureza, mas facultando-lhe um conjunto de informações sobre, por exemplo, a poluição, a reciclagem ou similares, que a criança apreende sem, todavia, perceber o significado, ou apelando para a sua responsabilidade ambiental sem que a criança tenha atingido o estádio que Ihe permita interiorizar o que se Ihe transmite. Observando as crianças na natureza é evidente que, diferentemente dos adultos para quem o mundo natural é, sobretudo, encarado como uma rectaguarda da acção, aquela constitui uma contínua fonte de estímulos para a sua actividade e constitui mesmo a componente integral da actividade. Digamos que a criança experiencia o mundo natural de modo holístico. Algo que é ignorado por alguns projectos pedagógicos, em que, para todas as faixas etárias, a educação no ambiente (outdoor education) promove sobretudo a formação de capacidades de observação e experiência directa de interpretação ambiental. As diferenças entre os projectos de educação, quer a nível nacional quer internacional, são substanciais, divergindo em orientações pedagógicas e em objectivos. Em traços gerais, consideram-se aqui duas linhas distintas escoradas em sólidas fundamentações que se repercutem em programas de educação ambiental específicos. Se uma linha defende que o propósito da educação ambiental é o de responder já aos problemas que a crise ecológica implica como, por exemplo, as alterações climáticas, a perda da biodiversidade, entre outras ameaças à vida humana e planetária e, neste caso, a educação ambiental será sobretudo uma via de enfrentamento e de resolução dos problemas ambientais que elege uma perspectiva comportamentalista popular entre os ambientalistas e, de certo modo, convergente com os programas da Educação para o Desenvolvimento Sustentável (EDS) implementados pelas Nações Unidas e inspirados pela Cimeira do Rio (1992), pela Agenda XXI entre outros (recorde-se que a década de 2005 a 2014 foi declarada a década da EDS, agilizada pela UNESCO); a outra linha, cuja objecção principal àquela abordagem é a de que o que está em causa aqui é educação e não treino ou condicionamento, incide sobretudo no desenvolvimento de todo o potencial humano na sua dimensão planetária, adoptando 
uma feição claramente pedagógica e construtivista. Neste sentido, assinalamos, positivamente, a emergência de programas que tendem para o entendimento da EA como agente de formação integral do ser humano, enquanto ser social inserido no ambiente natural e em conexão com ele. Os japoneses, por exemplo, promovem experiências na natureza em programas ecoescolas para todas as idades com o objectivo de induzir o sentimento estético da natureza e o de adquirir conhecimentos sobre ela, como binómio que constitui a base do pensamento e da acção. Também o projecto ambiental nas escolas do Distrito Florestal do Condado de Cook, no Illinóis, entende a educação ambiental (para a conservação) segundo fundamentos educativos que incluem o pensamento científico, o sentimento estético e a cidadania enquanto dimensão actuante do ser humano na sociedade e na natureza ${ }^{23}$. Registam-se, ainda, outros exemplos similares bem-sucedidos no norte da Europa (Alemanha, Escócia, Holanda, Suiça).

Incipiente em quase todos os programas, que privilegiam a componente cognoscitiva, é o enfoque no fortalecimento do vínculo afectivo com as realidades naturais, mesmo que, na sessão de conclusões de uma determinada actividade se constate, com frequência, que o que causou maior impacto nos participantes foram precisamente sensações (tocar a pele de um animal) e emoções (repulsa e medo ou admiração) ${ }^{24}$.

Cremos que a divergência teórica das duas grandes linhas que informam o entendimento da $E A$, não será um obstáculo à sua implementação conjuntiva na prática se se considerar que cada estádio do desenvolvimento humano exige estímulos diferenciados. Neste sentido, reafirmamos com Wilson, Kellert, Kahn, Sobel e tantos outros que o ponto de partida da aprendizagem ambiental, ser sensível à natureza, deverá perfilar-se no sentido de uma re-educação do olhar, do cheirar, do tocar,

23 Cf. Gonzalez-Gaudiano, 2005. Este livro oferece um bom panorama das divergências de princípios e estratégias e dos conflitos daí decorrentes entre as diferentes versões de Educação Ambiental.

24 Cf. Gonzalez-Gaudiano, 2005, 66. A este respeito citamos Kellert: «These affective encounters with animals and with nature in general, tend to be so significant that most adults looking back on their childhood cite the natural world as an emotionally critical aspect of their youth» (Kellert, Nature and Childhood Development. On-line, acesso Dezembro de 2013). 
do ouvir, em contacto directo com as realidades naturais, espoletando deste modo o entranhamento do mundo natural que revela os sentimentos de afinidade e ligação cósmicas e propicia o conhecimento e o agir enraizados no amor e no respeito, como pretendia Leopold. Vertendo estas determinações num projecto programático de educação ambiental e seguindo o modelo de Kellert (e um vasto conjunto de autores na mesma linha, entre os quais destacamos David Sobe ${ }^{25}$ ) avançamos com os princípios fundamentais a ter em conta, a nosso ver, na abordagem específica e técnica a esta matéria:

Segundo Kellert (2002 e 2005) são três os estádios pedagógicos:

A - Primeira infância (3-7 anos);

B - Idade escolar (7-11 anos);

C - Adolescência (12-17 anos);

A - Na primeira infância, como já foi afirmado, a educação ambiental deve centrar-se no desenvolvimento da empatia com o ambiente natural, através do contacto com animais, plantas, rios, lagos, enfim, todas as fontes naturais capazes de proporcionar sentimentos de prazer e alegria. Esta concepção pedagógica é aplicada com sucesso desde os anos 90 na Alemanha no que é designado por Waldkindergärtens onde as crianças pequenas passam o dia inteiro, mesmo em condições adversas, no exterior. Um exemplo seguido em países como a Escócia, Noruega, Suiça, Áustria, e em Wisconsin nos EUA ${ }^{26}$.

B - Neste estádio o conceito-chave da educação é o de exploração. Todo o tipo de jogos - caça ao tesouro, apanhada, escalada, seguir por veredas, procurar pistas nos trilhos do mato - e actividades como jardinagem, agricultura, pesca que respondem a questões básicas como, por exemplo, de onde vem a comida? são modos de desenvolver o interesse

25 Cf. as obras de David Sobel sobre o tema: 1996, Beyond Ecophobia: Reclaiming the Heart of Nature Education, Great Barrington, MA, The Orion Society; 2002, Children's Special Places: Exploring the Role of Forts, Dens, and Bush Houses in Middle Childhood, Detroit, Wayne State University Press; 2004, Place-Based Education, Connecting Classrooms \& Communities, Great Barrington, MA, The Orion Society; 2008, Children and Nature: Design principles for educators, Portland ME, Stenhouse Publishers.

26 https://www.schlitzaudubon.org/learn/nature-preschool/. 
pela natureza e adquirir alguns conhecimentos básicos sobre os seus processos.

C - A adolescência confronta-se com a problemático do "eu" na sua relação com o mundo. Os grandes ideais de "salvar o mundo" emergem aqui e prolongam-se para além dos 17 anos. O compromisso planetário, a preservação ambiental e o conhecimento concreto implicados no desejo de salvação do planeta serão os conceitos modeladores desta fase. Dito de outro modo, é importante fomentar o interesse e o conhecimento pela realidade natural que circunda o jovem - o rio vivo na sua memória da infância, o matagal em que tantas vezes brincou e que agora vai ser substituído por edificado, os campos relvados, enfim realidades que fazem parte da sua experiência vivida e que, de algum modo, se degradaram ou estão em vias de desaparecimento. Ou, ainda, que, continuando lá, constituem fontes de informação bio-ecológica a conhecer e a aprofundar.

Julgamos que a compreensão das necessidades específicas de cada um destes estádios não afectará a necessidade de promover mudanças comportamentais objectivas relativamente a ameaças ecológicas prementes. Pois o que, fundamentalmente, está em causa é a passagem dos sentimentos ético-estéticos a uma acção engajada, comprometida com o ambiente. Uma versão de pendor mais instrumental e utilitarista e com um enfoque político-económico explícito da EA dirigida às populações em geral, de ordem mais conjuntural, portanto, não deve subestimar uma versão cujo escopo é fundamentalmente pedagógico em vista à formação do cidadão futuro, de ordem predominantemente estrutural. Pelo contrário, a perspectiva desenvolvimentista e construtivista dirigida para as aquisições da $1^{\text {a }}$ infância até ao final da adolescência deverá ser considerada no esforço para a integração formal da EA no sistema educativo, tendência crescente nas políticas educativas de vários países do globo cujo horizonte é, justamente o de promover e desenvolver na criança e no adolescente uma acção comprometida com o meio natural, motivada por valores de respeito, empatia e admiração. Um esforço que, diga-se, esbarra com um sem número de questões que se colocam à educação ambiental (o que deve ser ensinado? como? por quem? há uma relação causal entre o conhecimento e uma efectiva alteração comportamental?), sobretudo no momento em que vivemos, o de "sociedade 
em risco", produto de um crescimento e de um consumo sem limites, das "armadilhas" da globalização que engendra níveis de complexidade crescentes e desemboca num horizonte de imprevisibilidade, incerteza, controvérsia e conflito. De qualquer modo, assinala-se (Teixeira, 2003) a evolução notável no interior da EA no sentido da transição «de uma 'educação sobre o ambiente' (elemento empírico), de uma 'educação no (/do) ambiente' (elemento estético), ou de uma 'educação para o ambiente' (elemento ético)» para «uma educação com o ambiente (...) evoluindo os seus agentes do papel de técnicos do ambiente para o denodo de educadores, em vincado privilégio da pessoa (a educar)» ${ }^{27}$.

4. Dado o exposto, cremos que apenas uma consciência superficial ou uma cínica indiferença podem ignorar que os sinais de alarme que a natureza emite exigem do ser humano o compromisso sério consigo próprio e com a sua casa comum. Um compromisso (ético) no qual estão investidas todas as dimensões do seu ser - sensibilidade, afectividade, entendimento, razão. A nosso ver, escorados pela literatura considerada e à boa maneira rousseana, é, por conseguinte, na educação, entendida como cultura de valores que subsumem a harmonia entre o ser, a sociedade e o meio natural onde todos os actos se presentificam, que se encontram e acham os fundamentos para o agir ambientalmente responsável.

Neste sentido, reafirmamos que a educação do humano aberta ao belo e ao sublime naturais constitui uma possibilidade exemplar de realização autêntica da liberdade e da responsabilidade. Longe de significar uma negação da liberdade, a ética ambiental, na sua riqueza e amplitude multidisciplinares, propõe-nos um modelo de educação cuja acepção de liberdade afecta o ser humano de máxima amplitude e dignidade, exprimindo plenamente o sentido da segunda formulação kantiana do imperativo categórico:

«Age como se a máxima da tua acção se devesse tornar, pela tua vontade, lei universal da Natureza» ${ }^{28}$.

27 Teixeira, 2003, 94.

28 «Handle so, als ob die Maxime deiner Handlung durch deinen Willen zum allgemeinen Naturgesetze warden sollte» (Kant in Soromenho-Marques, 1998, 147-148). 


\section{Referências}

Assunto, R., 2011 , A Paisagem e a Estética. In: Filosofia da Paisagem. Uma Antologia, trad. Pedro Sargento, Lisboa, CFUL, 341-375.

Carson, R., 2012, Maravilhar-se, trad. José Carlos Marques, Porto, Edições-Sempre-em-Pé/Campo Aberto.

Emerson, R.W., 2001, A Natureza, trad. Berta Bustorff Silva, Cascais, Sinais de Fogo.

Gonzalez-Gaudiano, E., 2005, Educação Ambiental, Lisboa, Instituto Piaget.

Jonas, H., 1998, Pour une Éthique du Futur, trad. Sabine Cornille et al., Paris/S. Germain: Ed. Payot et Rivages, [1992, 1993].

Kahn Jr.,P., 2002, Children's Affiliations with Nature: Structure, Development, and the Problem of Environmental Generational Amnesia. In: Children and Nature. Psychological, Sociocultural and Evolutionary Investigations, Cambridge/Massachusetts, M.I.T, 93-116.

Kellert, S., 2002, Experiencing nature: Affective, cognitive, and Evaluative Development. In: Children and Nature. Psychological, Sociocultural and Evolutionary Investigations Cambridge/Massachusetts, M.I.T, 117-151.

Kellert, S., 2005, Building for Life: Designing and Understanding the Human-Nature Connection, Washington DC, Island Press.

Kellert, S., 2012, Birthright People and Nature in the Modern World, New Heaven, Yale University Press.

Kellert, S. and Wilson, E.O., 1993, The Biophilia Hypothesis, Washington DC, Island Press.

Kellert, S. and Kahn Jr., P., 2002, Children and Nature. Psychological, Sociocultural and Evolutionary Investigations, Cambridge/Massachusetts, M.I.T.

Kirchof, E., 2008, Estética e Biossemiótica, Porto Alegre, EDIPUCRS.

Krishnamurti, 1992, O Despertar da Sensibilidade, trad. Beatriz Branco, Lisboa, Editorial Estampa.

Leopold, A., 1949, A Sand County Almanac and Sketches Here and There, New York, Oxford University Press. 
Soromenho-Marques, V., 1998, O Futuro Frágil, Lisboa, Publicações Europa-América.

Teixeira, F., 2003, Educação Ambiental em Portugal - Etapas. Protagonistas e Referências Básicas, Lisboa, LPN.

Wilson, E., 1984, Biophilia, the human bond with other species, Cambridge, Massachusetts, London, Harvard University Press.

Varandas, M.J., 2003, Simbiose Benevolente e Comunidade. In: Ética Ambiental, uma ética para o futuro, Lisboa, CFUL, 107-115.

Varandas, M.J., 2016, A Natureza: Solo de Conjunção da Ética e da Estética, Saarbrücken, Deutschland, Novas Edições Académicas. 